\title{
Procesos urbanos recientes en el Área Metropolitana de Concepción: transformaciones morfológicas y tipologías de ocupación 1
}

\author{
Edison Salinas Varela² y Leonel Pérez Bustamante ${ }^{3}$
}

\begin{abstract}
RESUMEN
Para conocer los recientes procesos de ocupación metropolitanos se ha elaborado una metodología basada en la fotointerpretación de imágenes aéreas e información censal. Esta metodología se aplica en el Área Metropolitana de Concepción (AMC), para los años censales 1992 y 2002. Del análisis se obtienen mapas y tablas estadísticas que sintetizan aspectos relevantes del proceso de crecimiento de las áreas urbanas desde una perspectiva morfológica, así como las tipologías de ocupación de suelo urbano y el impacto que estas tienen sobre la variación de densidad de población urbana, a escala metropolitana y comunal. Los resultados muestran que durante el periodo de estudio el AMC tiene un crecimiento urbano importante, producto principalmente del consumo de suelo industrial y residencial, que a su vez impacta negativamente en la densidad de población urbana.
\end{abstract}

Palabras clave: Área Metropolitana de Concepción, ocupación urbana, crecimiento urbano, expansión urbana, consumo de suelo.

\begin{abstract}
To understand the recent processes of metropolitan occupation, a methodology based on visual interpretation of aerial and satellite images and census data has been developed. This methodology has been applied on the Metropolitan Area of Concepción (MAC), for the census years 1992 and 2002. This analysis provides maps and statistical tables that allow synthesizing relevant aspects of the growth processes of urban areas from a morphological perspective; as well as the types of occupation of urban land and the impact these have on the variation of urban population density on a metropolitan and municipal scale. The results show that during the study period, the MAC had a significant urban growth, mainly resulting from the consumption of industrial and residential land, condition that, at the same time, produced a negative impact on the urban population density.
\end{abstract}

Key words: Metropolitan Area of Concepción, urban land cover, urban growth, urban sprawl, land consumption.

Proyecto FONDECYT Regular № 1080566: "Transformaciones del Concepción Metropolitano. Estudio de las formas de crecimiento urbano a través de los grandes conjuntos residenciales (1992-2006)". Artículo recibido el 10 de marzo de 2010, aceptado el 25 de agosto de 2010 y corregido el 14 de octubre de 2010.
2 Escuela de Arquitectura, Universidad de Talca (Chile). E-mail: edisonsalinas@gmail.com

3 Facultad de Arquitectura, Urbanismo y Geografía y Centro EULA, Universidad de Concepción (Chile). E-mail: leperez@udec.cl 
Actualmente se ha acumulado importante evidencia de que las ciudades latinoamericanas están siguiendo un patrón de cambio similar a lo observado en contextos europeos y norteamericanos. Se trata principalmente de cambios en los dos aspectos base de la ciudad: la forma y la función. A grandes rasgos, lo que ha caracterizado esta trasformación es la modificación morfológica en relación con atributos de contigüidad, compacidad y límite del modelo histórico de ciudad, por los de discontinuidad, fragmentación o difusión de lo urbano contemporáneo. Junto con esto, la intensificación de las interacciones entre núcleos urbanos de relativa cercanía expande la ciudad más allá de los límites administrativos, apareciendo conceptos como ciudades en red, policentrismo y ciudad región (Portas, 2004).

Mientras que en el aspecto funcional se afirma que las tendencias actuales de policentralidad pueden favorecer al desarrollo equilibrado de los sistemas urbanos (Comisión Europea, 1999), en el caso de las transformaciones morfológicas las evidencias muestran un fuerte impacto negativo. Las transformaciones recientes, resultado de una ocupación explosiva del territorio, producen la dispersión de la ciudad y, con ella, la insularización de los espacios naturales con la consiguiente pérdida de biodiversidad, la impermeabilización y el sellado de superficies, la distorsión del ciclo hídrico, la ruina de muchos valores paisajísticos, un excesivo consumo de materiales, de agua y de energía y, con ello, una alta emisión de contaminantes atmosféricos (Ministerio de Medio Ambiente, 2006). A este respecto, Pauchard et al. (2006) estudiaron la urbanización, la homogenización del paisaje y la pérdida de biodiversidad como procesos y como elementos en conflicto en el Área Metropolitana de Concepción (AMC), enfatizando en que la urbanización es considerada uno de los principales factores causantes de la pérdida de biodiversidad y homogenización del entorno natural y, concluyendo que este proceso se encuentra fuertemente asociado a la fragmentación de hábitat y a cambios en la estructura y composición de la biodiversidad.

El análisis de los cambios de ocupación del territorio que se producen como consecuencia de las diversas actividades humanas sobre el mismo, y por la dinámica natural de los ecosistemas, constituye un indicador de trascendental importancia para avanzar en el conocimiento de las potencialidades hacia un desarrollo más sostenible (OSE, 2006). Para el caso del AMC, ya en 1999, Azócar y Sanhueza (1999) ponían como ejemplos de ello la urbanización progresiva del sistema de humedales y otros sectores planos, y el confinamiento definitivo de grandes tramos de los ríos Biobío y Andalién, que atraviesan el núcleo central del AMC, por zonas residenciales e industriales. Más recientemente, Romero, Moscoso y Smith (2009) desarrollaron una sistemática evaluación ambiental de los efectos del crecimiento espacial en diversas ciudades y tres áreas metropolitanas chilenas -entre ellas el AMC-, concluyendo sobre el desmejoramiento de la calidad ambiental expresado entre otros factores por: cambios en el clima urbano y pérdida de calidad del aire; generación de islas de calor urbanas y disminución de islas frías; reducción y deterioro de cubiertas vegetales como terrenos de cultivo y áreas naturales (como humedales), pérdida de biodiversidad y reducción de hábitats. Se concluye acentuando no solo las pérdidas y afectaciones, sino también el aumento de riesgos por inundaciones, anegamiento o aluviones. La descripción detallada de los procesos de ocupación del territorio es por tanto un paso esencial para su entendimiento, posibilitando su explicación, en base a muy diversos tipos de factores y ayudando a generar elementos de intervención mediante alguna forma de ordenación del territorio.

Este complejo marco de transformaciones y el impacto del proceso urbanizador sobre los territorios determinan que en la actualidad existan numerosas instituciones abocadas al estudio de las áreas urbanas. A mediados de los años ochenta surgen iniciativas para monitorear los procesos de ocupación y evaluar el impacto de las transformaciones de los territorios. Proyectos como CORINE Land Cover o el proyecto MOLAND, desarrollados por la Agencia Europea del Medio Ambiente (European Environment Agency, EEA) para todo el territorio europeo, como también las investigaciones desarrolladas por el Servicio Geológico de Estados Unidos (USGS), han generado completas bases de datos, así como un marco metodológico general sobre el cual se han basado las investigaciones locales, 
que han permitido a su vez ampliar, comparar y obtener nuevos niveles de desagregación de la realidad territorial.

En Latinoamérica, pese al significativo aumento de la población urbana y los evidentes cambios en las ciudades en general, las iniciativas de estudios sobre la ocupación y urbanización del territorio son todavía escasas y aisladas, siendo una tarea pendiente la creación de protocolos y bases de datos conjuntas que permitan un seguimiento de estos procesos. En Chile este tipo de estudios son hoy en día indispensables dado el importante proceso urbanizador que ha vivido el país en los últimos años, que lo sitúa entre los países con mayor porcentaje de población urbana del planeta. En ese sentido es importante señalar algunos esfuerzos por recoger y organizar información relacionada con la ocupación urbana en todo el territorio, especialmente los realizados por el Observatorio Urbano del Ministerio de Vivienda y Urbanismo (OU, 2007). Sin embargo, estas iniciativas siguen siendo aisladas y a diferencia de los proyectos europeos, no generan protocolos metodológicos y los datos geográficos resultantes son insuficientes para desarrollar investigaciones de mayor especificidad.

Desde este contexto el presente trabajo ensaya un análisis espacio-temporal para conocer las transformaciones recientes de una ciudad latinoamericana y observar sus dinámicas y patrones de crecimiento. Dentro de sus objetivos se plantea elaborar una metodología para el monitoreo de áreas urbanas basada en proyectos internacionales, construyendo una base de datos con información de fácil acceso y con procesos relativamente simples. Con esta metodología se espera obtener algunos indicadores básicos que aporten en la discusión acerca de los modelos de ciudad latinoamericana y su semejanza con lo documentado para las ciudades europeas y norteamericanas: ¿crece de forma excesiva?, ¿aumenta el consumo de suelo?, ¿cuáles son los tipos de ocupación predominantes?, ¿aumenta la ocupación de baja densidad?

Como ámbito de estudio se elige el Área Metropolitana de Concepción, el segundo conglomerado urbano en importancia demográfica y económica del país. Dada su reciente configuración metropolitana y tamaño medio, entrega ventajas en cuanto a la observación y estudio del fenómeno urbano; se puede afirmar además que, a grandes rasgos, su proceso de urbanización y crecimiento metropolitano son el futuro probable de muchas de las ciudades intermedias en desarroIlo en Chile.

El trabajo se organiza partiendo por definir y caracterizar el ámbito de estudio: el Área Metropolitana de Concepción. Posteriormente se muestra la construcción del método de análisis basado en experiencias internacionales; se explica la metodología de recogida de datos, tratamiento de la información y la confección de la base de datos geográficos, utilizando técnicas de fotointerpretación visual y herramientas de Sistemas de Información Geográfica (SIG). El tercer apartado consiste en la utilización de la base de datos para determinar tres indicadores de interés para el análisis urbano: la variación de superficie urbanizada (crecimiento urbano), la variación de densidad de población urbana y las tipologías de ocupación. Finalmente se concluye sobre la evolución de la ocupación de suelo urbano en el AMC en el periodo estudiado y los patrones y dinámicas de ocupación en el desarrollo del conjunto metropolitano.

\section{Cambios y desafíos en los patrones de ocupación de suelo en las áreas metropolitanas}

Pero, ¿qué plantea la literatura acerca de las transformaciones recientes y el estudio de las tipologías de ocupación? Diversas investigaciones en las áreas urbanas latinoamericanas han evidenciado importantes transformaciones a nivel de estructura y fisionomía, con cambios vinculados a nuevos agentes económicos y culturales impulsados por la globalización. En el ámbito territorial, la descripción recurrente para estos cambios habla de una fragmentación de la ciudad, fuerte reflejo de las transformaciones sociales en proceso (Borsdorf, 2003; Janoschka, 2002; Janoschka, 2006). A este respecto, Borsdorf (2003) plantea que el elemento predominante de esta transformación es la masificación de los barrios cerrados, la aparición de cercos y muros como imagen recurrente de los nuevos 
proyectos inmobiliarios, similares a lo documentado en el caso de las gatted communities norteamericanas. Sin embargo, plantea que estas formas de exclusión y segregación poseen una larga data en América Latina, que los procesos de globalización y transformación económica han intensificado.

Las consecuencias urbanas, sociales y ambientales de estos procesos de crecimiento han sido analizadas en otras ciudades de América Latina y Chile (Taschner \& Bógus, 2001; Cariola y Labacana, 2003; Janoschka, 2006; Hidalgo, 2004; Hidalgo, 2007; Romero et al., 2009); y específicamente en las Ilamadas ciudades intermedias de Chile central (Azócar et al., 2003; Azócar et al, 2007), identificándose una clara relación entre el crecimiento de ciudades con intensificación de los procesos económicos de despliegue de inversiones en las regiones y procesos sociales de diferenciación según segmentos de población, exclusión y segregación urbanas, especialmente para los usos residenciales e industriales (Azócar et al., 2008; Borsdorf, 2000; Rovira, 2000).

Para Janoschka $(2002 ; 2005 ; 2006)$ la globalización y las transformaciones económicas de las últimas décadas han generado un nuevo modelo de ciudad latinoamericana cuyos principales rasgos son la fragmentación y privatización, reduciendo la polarización social y aumentando la segregación a escala reducida. El avance de este modelo ha significado la instalación progresiva de formas típicas de ciudades estadounidenses. Janoschka afirma que este modelo se ha generalizado por Latinoamérica, mostrando rasgos típicos en sus ciudades: la difusión de complejos habitacionales cerrados, la dispersión de grandes equipamientos comerciales, la instalación de complejos educativos adosados los barrios cerrados, la masificación de complejos habitacionales cada vez de mayor tamaño y autonomía, la modificación de la infraestructura de la líneas de tren, las autopistas, la suburbanización de la producción industrial y el aislamiento y falta de accesibilidad de los barrios de clase baja.

Es importante mencionar que la globalización no es el único agente de transformación, pues coexiste con factores y agentes locales que operan desde antes como han planteado Cariola y Lacabana (2003) en su investigación para la ciudad de Caracas. En el caso de Chile, hace casi tres décadas, López (1981) señalaba como factores relevantes que determinan el crecimiento y expansión de las ciudades, entre otros, la preferencia de la áreas urbanas como concentradoras de oportunidades; el factor socioeconómico implícito en el mayor requerimiento de inversión en el proceso de densificación, frente a la economía presente en la ocupación periférica; el sistema de avalúos rurales y urbanos; las preferencias de los usuarios por ambientes alejados y con características naturales; y la falta de políticas espaciales en la agricultura. Confirmando la participación de factores locales Azócar et al. (2010) señalan que en Chile los procesos de crecimiento urbano se han caracterizado por una urbanización reciente, acelerada por la incorporación de inversiones productivas destinadas principalmente a la extracción de recursos naturales en los territorios de influencia de las ciudades, y promovida por los mercados inmobiliarios y las políticas públicas en materia de construcción de viviendas por segmentos socioeconómicos (Azócar et al., 2010).

Estas formas de crecimiento urbano han sido confirmadas para Santiago de Chile en diversos estudios (Hidalgo, 2004; Borsdorf e Hidalgo, 2005; Ducci, 2002). El estudio de Ducci (2002) profundizó acerca de las características físico-territoriales de estos cambios para el Área Metropolitana de Santiago (AMS). A través de la medición y caracterización de la mancha urbana y los patrones de crecimiento para los años 1992 y 2000, sintetiza los procesos relevantes del AMS; la expansión a modo de mancha de aceite del suelo urbanizado, con un importante crecimiento del suelo industrial en patrones distintos a los del Plan Regulador Metropolitano, así como una persistente segregación espacial de las áreas residenciales, conformando una nueva estructura urbana que tendrá fuertes requerimientos en servicios e infraestructuras, así como en vialidad y transporte, siendo un posible escenario de nuevos conflictos sociales.

Al investigar el fenómeno en otras áreas urbanas chilenas las recientes transformaciones describen un panorama similar al presentado para Latinoamérica y para el 
AMS. Los estudios sobre Chillán (Azócar et al., 2003), Los Ángeles (Azócar et al., 2008), Concepción (Rojas et al., 2009a; Pérez y Salinas, 2007) y ciudades menores y alejadas como Coyhaique (Azócar et al. 2010), son descritas como ciudades fragmentadas territorial y socialmente, donde emprendimientos inmobiliarios y proyectos estatales configuran ciudades a modo de mosaicos de segregación y dispersión.

Para el Área Metropolitana de Concepción se han desarrollado algunas aproximaciones en este sentido. Rojas et al. (2009b) han estudiado las dinámicas de crecimiento urbano buscando sus patrones de crecimiento y su adecuación a los tipos de ciudad compacta o dispersa. Para ello cuantifican las superficies urbanizadas en distintos periodos de tiempo, permitiendo entender las tendencias de las formas urbanas resultantes y determinando la existencia de complejidad, dispersión y/o fragmentación del territorio. Baeriswyl (2009), en tanto, ha desarrollado un enfoque destinado a establecer la existencia de patrones de crecimiento que determinan el desarrollo del sistema urbano del Gran Concepción, sobre la base de un modelo de consumo de suelo, para determinar los posibles escenarios de crecimiento futuro y las implicancias territoriales de estos en el tiempo. Pérez y Salinas (2007) estudiaron las "nuevas" formas de crecimiento del AMC, desde un doble punto de vista: los tipos (formas físicas resultantes) y los procesos (su desarrollo en tiempo y localización territorial), durante el período 1992-2002, surgidas como manifestaciones de reestructuración y cambio en las lógicas de crecimiento urbano que la afectan en tanto que ciudad de escala y tamaño intermedio. Se analizaron 11 grandes sectores o áreas de crecimiento residencial y terciario, identificándose 6 tipos de crecimiento urbano.

Pero así como las definiciones y teorías sobre modelos urbanos permiten situarse en un nuevo contexto y las dinámicas de la urbanización generan nuevas realidades territoriales; es necesario concebir herramientas y métodos de aproximación para evaluar y comprender estos fenómenos. Más allá del encaje de estos análisis con un determinado modelo, se trata de desarrollar instrumentos para identificar características y tendencias en la ocupación que sean útiles para la planificación. Dentro de estos nuevos métodos y herramientas, el estudio de la ocupación de suelo a través de sistemas de información geográfica es ampliamente usado como forma de aproximación y evaluación de las transformaciones y patrones de crecimiento de las nuevas zonas urbanas, como también para analizar los factores que inciden en el mismo a través del análisis espacial cuantitativo de las relaciones entre diversas variables (Plata et al., 2009).

Chuvieco (1985) define la ocupación de suelo como el proceso que tiene como objetivo fundamental la cartografía e inventario de la cobertura o utilización de un determinado uso. Advierte que esta definición engloba dos concepciones bien diferenciadas: por un lado la ocupación o cobertura de suelo (land cover) que designa aquellos materiales presentes en un momento determinado sobre un superficie en concreto, y por otro el uso de suelo (land use) referido a las actividades que en esta superficie se desarrollan.

A pesar de que en los estudios mencionados ha tenido especial relevancia metodológica el uso de herramientas y Sistemas de Información Geográfica (SIG) y de técnicas de modelación de cambio de uso del suelo (Azócar et al., 2007; Aguayo et al., 2007; Henríquez et al., 2006), la mayor parte de los trabajos realizados dan cuenta de aproximaciones enfocadas a los aspectos sociales y/o ambientales como factores que han orientado los cambios recientes de las ciudades intermedias chilenas. De ellos se desprende la necesidad de estudiar los cambios morfológicos en la ocupación de suelo en las áreas metropolitanas, con mayor precisión y rigor científico; para identificar y comprender los patrones de ocupación con mejores pautas de medición para estos objetivos.

\section{Ámbito de estudio: el Área Metropolitana de Concepción}

El Área Metropolitana de Concepción se localiza en la Región del Biobío (Figura No 1), Octava Región de Chile, en la provincia de Concepción. La provincia está conformada por trece centros urbanos, tiene una superficie de $3.439 \mathrm{~km}^{2}$ equivalente al 9,27\% de la 
región y una población de aproximadamente un millón de habitantes, equivalentes al $48,5 \%$ de la población regional.

El AMC es la segunda concentración urbana del país después del Área Metropolitana de Santiago (AMS) (INE, 2002). Posee una variada e importante actividad económica basada en la industria (forestal, minera, pesquera y manufacturera, entre otras) y es también un importante centro de servicios. Es además un enclave estratégico nacional debido a que confluyen en su territorio cuatro modos de transporte: aeroportuario, portuario marítimo, ferroviario y vial.

El territorio que ocupa el AMC desde el aspecto físico se caracteriza principalmente por tres elementos: el borde costero, con las bahías de Concepción, San Vicente y Coronel; el río Biobío; y el complejo montañoso costero denominado cordillera de la Costa o de Nahuelbuta. Estos elementos y características morfológicas han sido influyentes en los procesos de asentamiento, configuración y crecimiento de sus núcleos urbanos.

Su configuración metropolitana comienza a mediados de 1950, cuando un proceso de industrialización tardío trajo consigo una importante migración campo-ciudad. Esta hizo crecer de manera significativa las principales áreas urbanas, intensificando los procesos de interacción y conurbación que hasta esa fecha eran incipientes (Pérez y Salinas, 2007). Los evidentes cambios en la ocupación del territorio llevaron a plantear en el año 1963 el Plan Intercomunal de Concepción, que puede considerarse la base de la planificación metropolitana y la consolidación de un área supramunicipal como entidad territorial.

Figura $N^{\circ} 1$

Localización y datos principales del Área Metropolitana de Concepción
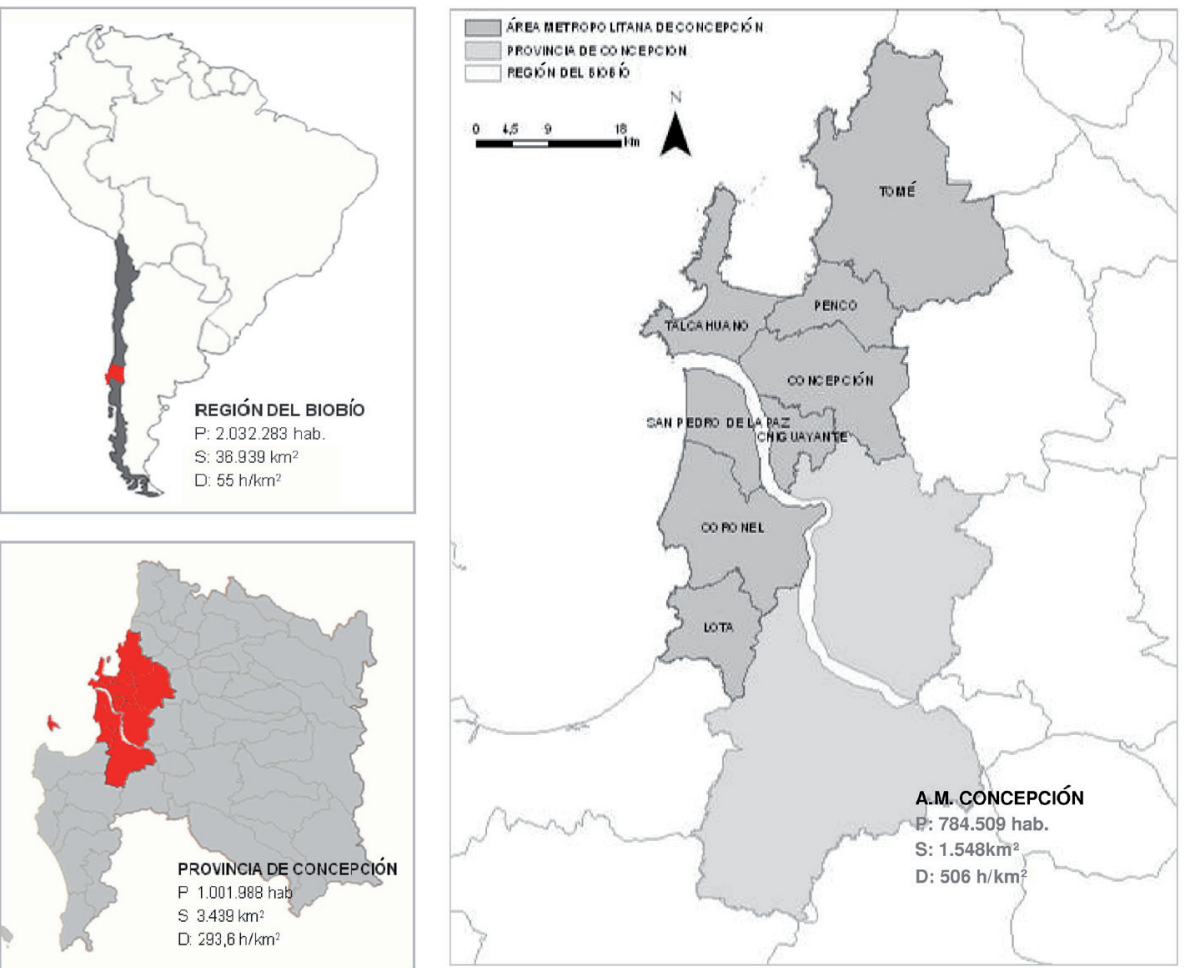

Fuente: Elaboración propia. 
Desde entonces la configuración del área metropolitana, tanto física como administrativa, ha tenido importantes transformaciones. En el aspecto físico, la constante expansión urbana y la creciente conurbación ha hecho evidente el carácter unitario y metropolitano, así como la necesidad de la planificación conjunta. Administrativamente, el área metropolitana ha ido aumentando paulatinamente el número de comunas, debido por una parte a la división de comunas de mayor población ${ }^{4}$, y por otra, a la inclusión de nuevas comunas en los planes sucesores al Plan Intercomunal, el Plan Regulador Metropolitano de Concepción de 1980 y su homónimo del año 2003.

Tal como afirman algunos autores (Rojas et al., 2009a) el alcance funcional del área metropolitana es complejo, y ha generado delimitaciones contradictorias. Con el fin de precisar su definición y límites, así como para

\footnotetext{
4 Algunos ejemplos: en el año 1995 se creó la comuna de San Pedro de la Paz y en 1996 la comuna de Chiguayante, ambas formadas de la comuna de Concepción. En el año 2003 se crea la comuna de Hualpén de una división de la comuna de Talcahuano. Actualmente están en proyecto de formación 2 nuevas comunas: Dichato y Andalién.
}

facilitar la comparación de los datos resultantes, se ha definido el Área Metropolitana de Concepción según la definición utilizada por la Dirección de Desarrollo Urbano (DDU) del Ministerio de Vivienda y Urbanismo (MINVU). Esta definición quedó establecida en el censo del año 2002 por el Instituto Nacional de Estadística (INE, 2001) y en los trabajos del Observatorio Urbano del MINVU (OU, 2007).

Según esta definición, las ocho comunas que constituyen el Área Metropolitana de Concepción son: Concepción, Coronel, Chiguayante, Lota, Penco, San Pedro de la Paz, Talcahuano y Tomé (Cuadro $N^{\circ} 1$ ). El área constituida por estas ocho ciudades y sus respectivos territorios comunales es en total 154.782 ha, la mitad del territorio provincial y apenas un $4 \%$ del total regional. Para el año 2002 concentraba un $42 \%$ de la población regional y un $87 \%$ de la población provincial.

\section{Metodología}

Uno de los objetivos planteados fue trabajar a partir de una metodología que permita obtener resultados comparables con investigaciones desarrolladas en Latinoamérica y Europa, así como con futuras investigaciones

Cuadro $\mathrm{N}^{\circ} 1$

Distribución de población, viviendas y superficie por comunas en el AMC

\begin{tabular}{|l|r|r|r|r|r|}
\hline \multicolumn{1}{|c|}{ Comuna } & \multicolumn{1}{c|}{$\begin{array}{c}\text { Población } \\
1992\end{array}$} & $\begin{array}{c}\text { Población } \\
2002\end{array}$ & $\begin{array}{c}\text { Viviendas } \\
1992\left(\mathrm{~N}^{\circ}\right)\end{array}$ & $\begin{array}{r}\text { Viviendas } \\
2002\left(\mathrm{~N}^{\circ}\right)\end{array}$ & $\begin{array}{c}\text { Superficie } \\
(\text { ha })\end{array}$ \\
\hline Concepción & 206.829 & 216.061 & 49.820 & 61.421 & 21.892 \\
Coronel & 83.422 & 95.528 & 20.215 & 26.600 & 27.806 \\
Chiguayante & 56.371 & 81.302 & 12.956 & 22.255 & 7.495 \\
Lota & 50.256 & 49.089 & 11.315 & 13.037 & 11.464 \\
Penco & 40.359 & 46.016 & 9.253 & 12.216 & 10.777 \\
San Pedro de la Paz & 67.817 & 80.447 & 15.916 & 21.699 & 11.258 \\
Talcahuano & 248.532 & 250.348 & 55.016 & 65.053 & 14.578 \\
Tomé & 49.269 & 52.440 & 12.556 & 15.915 & 49.514 \\
AMC & 802.855 & 871.231 & 187.047 & 238.196 & 154.782 \\
\hline
\end{tabular}

Fuente: Elaboración propia en base a datos del INE. 
a nivel nacional. Para esto se construye una metodología basada en la adaptación de proyectos europeos, que a través del establecimiento de protocolos permite a los investigadores obtener resultados comparables, posibilitando la construcción de metabases de datos a partir de información de distintas fuentes. Si bien la idea del trabajo es poder comparar los resultados, existe la necesidad de revisar y adaptar estas metodologías debido a diferencias en las fuentes de datos y a los objetivos específicos del presente trabajo enfocados al estudio de la ocupación urbana y por tanto a una clasificación reducida.

La estructura utilizada en el trabajo (Figura $\mathrm{N}^{\circ}$ 2) consiste en una primera etapa de recogida y organización de la información sobre el área de estudio partiendo de distintas fuentes. En una segunda etapa y como parte fundamental del trabajo se genera una base de datos geográfica específica para el área de estudio, que permite operar a través de un SIG información cartográfica y numérica proveniente de las diversas fuentes y formatos. Esta base se construye a partir de imágenes aéreas para los dos años estudiados, 1992 y 2002, siendo necesario realizar procesos de encaje, corrección y georreferenciación de imágenes. Luego, una vez definidas las categorías de clasificación, se realiza la fotointerpretación y digitalización de las áreas y tipos de ocupación. Con la base de datos generada se realizará el análisis para los periodos estudiados, los que serán mostrados por medio de mapas y tablas resultantes.

\section{Fuentes de datos}

Para el desarrollo de la presente investigación ha sido necesario integrar diversas fuentes de información. Como principales fuentes de datos se utilizan:

- Colección de fotografías aéreas del AMC del año 1992, en formato papel de $20 x$ $23 \mathrm{~cm}$, a escala 1:20.000 (cuya fuente es el Ministerio de Vivienda y Urbanismo, MINVU).

- Fotografías aéreas 2002-2006-2007 en formato digital JPG (cuya fuente es GoogleEarth).

- Otras series de fotografías aéreas del AMC años 1999-2000-2002 en formato digital TIFF y JPG (cuya fuente es el MINVU).

- Mapa SIG de distritos censales en formato Shapefile (cuya fuente es el Instituto $\mathrm{Na}$ cional de Estadísticas, INE) ${ }^{5}$.

- Censos de Población y Vivienda 19922002 en formato Redatam (cuya fuente es el INE).

\footnotetext{
5 Facilitados por la Facultad de Geografía de la Universidad de Concepción.
}

Figura $\mathrm{N}^{\circ} 2$

Diagrama metodológico

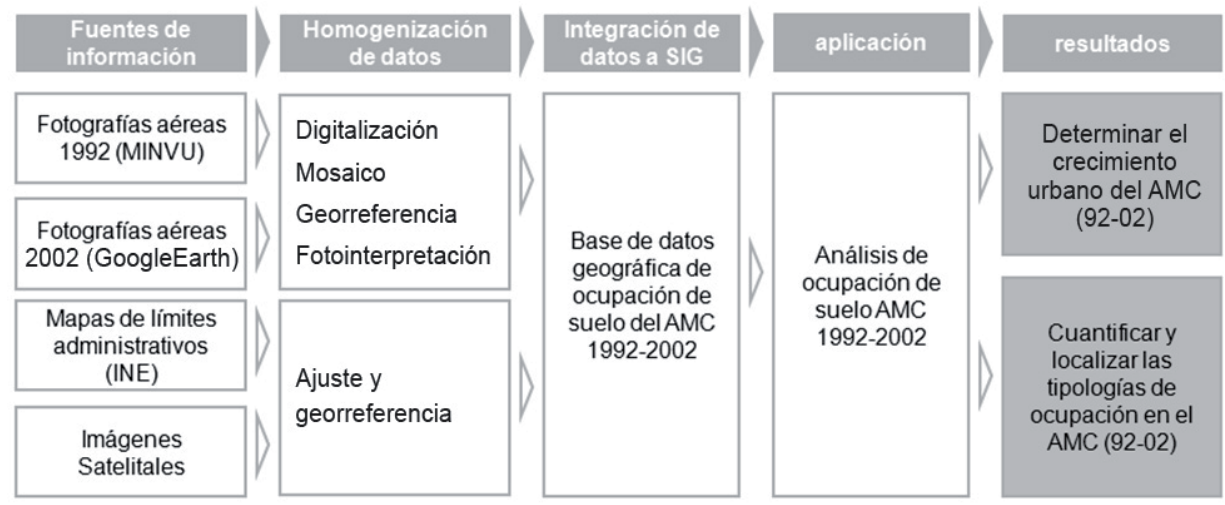

Fuente: Elaboración propia. 
- Imágenes satelitales Landsat 4/5 en formato GeoTiff (cuya fuente es el USGS).

\section{Clasificaciones y escalas}

Uno de los puntos claves del trabajo consistió en la definición del inventario de clases a utilizar en la clasificación. Como ya ha sido comentado, hasta la fecha no existe un marco de referencia para este tipo de investigacio- nes en Latinoamérica, por lo que se decide ocupar estándares europeos que permitan comparar los resultados, como también la posibilidad a futuro de generar una base de mayor amplitud.

Basándose en las categorías propuestas por el proyecto Corine Land Cover (EEA, 2006) se elabora una clasificación propia (Figura $N^{\circ} 3$ ) centrada específicamente en las

Cuadro $\mathrm{N}^{\circ} 2$

Descripción y ejemplos de tipologías de ocupación en el AMC

\begin{tabular}{|c|c|c|c|c|c|c|}
\hline \multirow{2}{*}{\begin{tabular}{|l}
\multicolumn{1}{|c}{$\begin{array}{c}\text { Nivel } 1 \\
\text { (CORINE) }\end{array}$} \\
$\begin{array}{l}\text { 1. Superficies } \\
\text { artificiales }\end{array}$
\end{tabular}} & \multicolumn{2}{|c|}{ Nivel 2 (CORINE) } & \multicolumn{2}{|r|}{ Nivel 3 (CORINE) } & \multicolumn{2}{|r|}{ Nivel 4 (Propia) } \\
\hline & 1.1 & $\begin{array}{l}\text { Zonas } \\
\text { urbanas }\end{array}$ & 1.1 .1 & $\begin{array}{l}\text { Tejido urbano } \\
\text { continuo }\end{array}$ & 1.1 .1 .1 & $\begin{array}{l}\text { Tejido residencial } \\
\text { continuo denso }\end{array}$ \\
\hline & & & & & 1.1 .1 .2 & $\begin{array}{l}\text { Tejido residencial } \\
\text { continuo densidad media }\end{array}$ \\
\hline & & & 1.1 .2 & $\begin{array}{l}\text { Tejido urbano } \\
\text { discontinuo }\end{array}$ & 1.1.2.1 & $\begin{array}{l}\text { Tejido residencial } \\
\text { discontinuo en bloques }\end{array}$ \\
\hline & & & & & 1.1.2.2 & $\begin{array}{l}\text { Tejido residencial } \\
\text { discontinuo de baja } \\
\text { densidad }\end{array}$ \\
\hline & & & & & 1.1.2.3 & $\begin{array}{l}\text { Tejido residencial } \\
\text { discontinuo disperso }\end{array}$ \\
\hline & 1.2 & Zonas & 1.2 .1 & Zonas industriales o & 1.2.1.1 & Áreas industriales \\
\hline & & $\begin{array}{l}\text { industriales, } \\
\text { comerciales }\end{array}$ & & comerciales & 1.2.1.2 & Áreas comerciales \\
\hline & & y de & & & 1.2.1.3 & Otras zonas artificiales \\
\hline & & transportes & 1.2 .2 & $\begin{array}{l}\text { Redes viarias, } \\
\text { ferroviarias y terrenos } \\
\text { asociados }\end{array}$ & 1.2.2.1 & Carreteras \\
\hline & & & 1.2 .3 & Zonas portuarias & 1.2 .1 .3 & Otras zonas artificiales \\
\hline & & & 1.2 .4 & Aeropuertos & 1.2.1.3 & Otras zonas artificiales \\
\hline & 1.3 & $\begin{array}{l}\text { Zonas de } \\
\text { extracción }\end{array}$ & 1.3 .1 & $\begin{array}{l}\text { Zonas de extracción } \\
\text { mineras }\end{array}$ & 1.2 .1 .3 & Otras zonas artificiales \\
\hline & & $\begin{array}{l}\text { minera, } \\
\text { vertederos } \\
\text { y en }\end{array}$ & 1.3 .2 & $\begin{array}{l}\text { Escombreras y } \\
\text { vertederos }\end{array}$ & 1.2.1.3 & Otras zonas artificiales \\
\hline & & construcción & 1.3 .3 & Zonas en construcción & 1.2 .1 .3 & Otras zonas artificiales \\
\hline & 1.4 & Zonas verdes & 1.4 .1 & Zonas verdes urbanas & -- & Sin clasificar \\
\hline & & agrícolas & 1.4 .2 & $\begin{array}{l}\text { Instalaciones } \\
\text { deportivas y recreativas }\end{array}$ & 1.2 .1 .3 & Otras zonas artificiales \\
\hline
\end{tabular}

Fuente: Elaboración propia a partir de EEA, 2006. 
superficies artificiales o construidas (Cuadro $N^{\circ} 2$ ). De esta se excluyen algunas ocupaciones difíciles de obtener por medio de la interpretación visual, sobre todo tratándose de imágenes fotográficas en blanco y negro como las disponibles para el año 1992. Un ejemplo son las áreas verdes urbanas, que además de ser difíciles de identificar y separar de otro tipo de suelos como pastizales, terrenos húmedos, entre otros, para el área de estudio presentan superficies mínimas de ocupación. También se decide reagrupar algunas categorías y no clasificar aquellas que son de menor interés para el estudio.

\section{Fotointerpretación}

El trabajo de fotointerpretación consistió en digitalizar en un programa SIG sobre las fotografías aéreas georreferenciadas los polígonos de ocupación, según los criterios de clasificación detallados anteriormente y siguiendo un protocolo de digitalización con el fin de realizar un trabajo homogéneo sobre toda el área de estudio. Dada la calidad de las imágenes y a los objetivos del estudio, se fija una escala de digitalización de 1:25.000 y la unidad mínima mapeable de 0,5 hectáreas.

\section{Resultados}

\section{Crecimiento del área urbanizada metropolitana 1992-2002}

La primera información obtenida a partir del análisis de las manchas es el crecimiento de la superficie urbana total del AMC (Figura $N^{\circ} 4$ y Cuadro No 3). En el año 1992 el AMC presenta una superficie urbana de 9.013 ha,

Figura $\mathrm{N}^{\circ} 3$

Descripción y ejemplos de tipologías de ocupación en el AMC

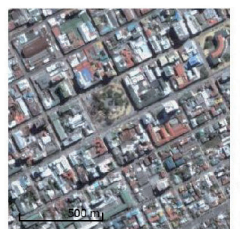

1.1.1.1 Tejido residencial continuo denso

Caracterizado por una alta ocupación, conformado por una mezcla de edificación con predominio de edificaciones colectivas y adosadas, estructura de calles regular y muy baja vegetación

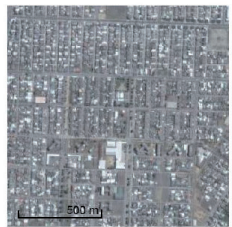

El porcentaje de suelo artificial estimado es sobre el $80 \%$

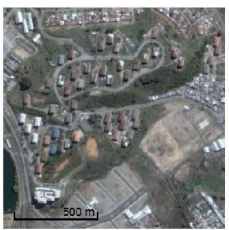

1.1.1.2 Tejido residencial continuo de medio denso

Caracterizado por una ocupación media-alta, compuesto principalmente por viviendas individuales adosadas, con una estructura de calles regular y baja vegetación.

El porcentaje de suelo artificial estimado es sobre el $80 \%$.

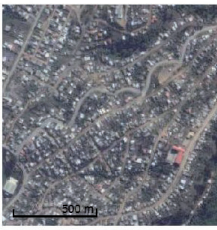

1.1.2.1 Tejido residencial discontinuo en bloques

Compuesto por edificaciones colectivas aisladas, de grandes dimensiones. Puede presentar ocupación por vegetación.

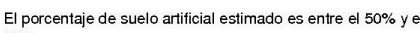
$80 \%$

1.1.2.2 Tejido residencial discontinuo baja densidad

Compuesto por edificaciones individuales aisladas, una estructura de calles más irregular, y generalmente algún grado de vegetación

El porcentaje de suelo artificial estimado es entre el $50 \%$ y el $80 \%$.

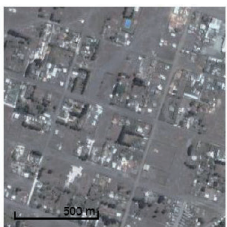

1.1.2.3 Tejido residencial discontinuo disperso

Compuesto por edificaciones individuales aisladas, débil estructura de calles, y generalmente mayor presencia de vegetación

El porcentaje de suelo artificial estimado es entre el $15 \%$ yel $50 \%$.

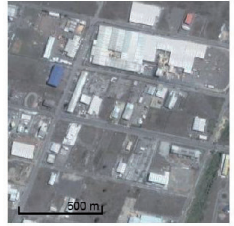

12.1. Áreas industriales

Formado por grandes edificaciones de formas simples $y$

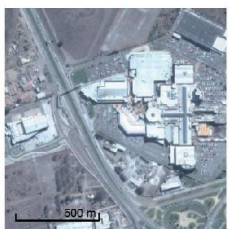

riadas y presencia de zonas de acopio y yransporte.

1.2.1.2 Áreas comerciales

Formada por grandes edificaciones 0 conjuntos de edificios zonas de servicio, como estacionamientos, parques y otros.

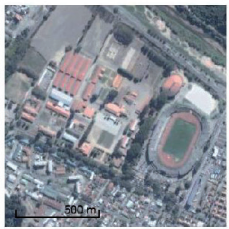

1.2.1.3 Otras zonas artificiales

Incluye todas aquellas supericies artificiales no incluidas en otras categorias, tales como: equipamientos deportivos, educacionales, militares, etc.

Fuente: Elaboración propia. 
mientras que en el año 2002 la ocupación urbana es de 10.293 ha, lo que significa un crecimiento de 1.279 ha, es decir un $14,2 \%$ con respecto a 1992 .

Figura $\mathrm{N}^{\circ} 4$

Sectores de crecimiento urbano años 1992-2002

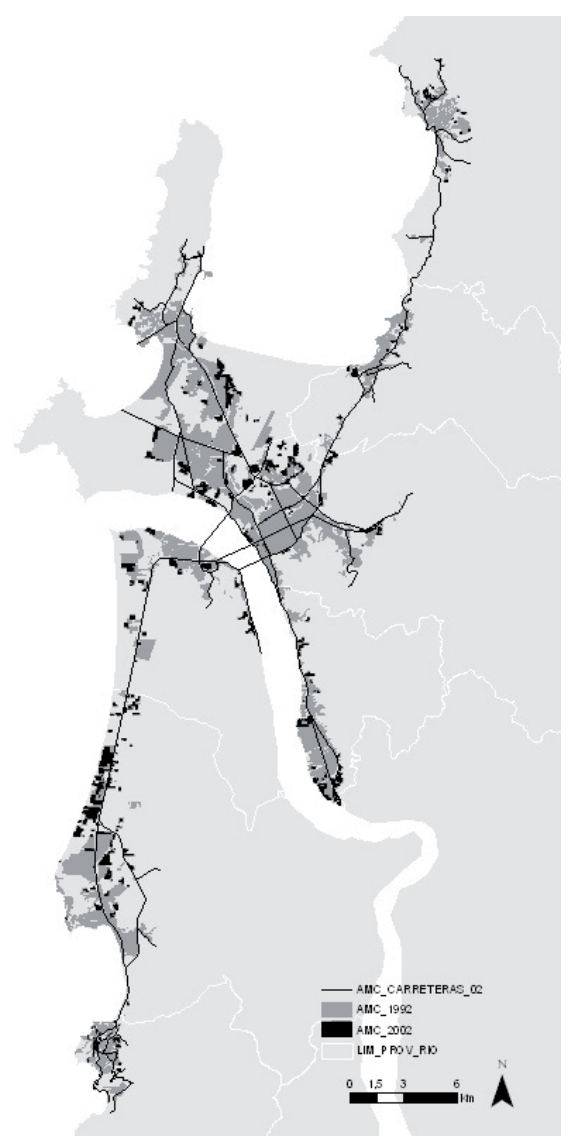

Fuente: Elaboración propia.

Si se compara la superficie urbanizada con el total del territorio metropolitano -es decir, con la suma de las superficies de las ocho comunas que componen el AMC- este crecimiento parece ser poco significativo: frente a las 154.872 ha totales, para el año 1992 la ocupación urbana es de un 5,8\% y para el 2002 de un 6,6\%. Sin embargo, este aumento de la mancha urbana en un periodo de diez años equivale a una superficie mayor a toda el área urbanizada de una comuna de tamaño medio como Coronel o San Pedro de la Paz o a más de dos veces el tamaño de comunas pequeñas como Lota, Tomé o Penco.

La desagregación de los datos a nivel comunal permite identificar una estructura metropolitana: las comunas centrales, prácticamente unidas en una gran mancha, son las de mayor tamaño: ocupan más de la mitad del territorio urbanizado sumando casi 5.000 ha en el año 1992. Un segundo grupo compuesto por Coronel y San Pedro de la Paz (con alrededor de 1.000 ha) y de tamaño un poco menor Chiguayante (738 ha) suman cerca de 2.500 ha. Luego se observa un tercer grupo de núcleos menores, Tomé, Penco y Lota con alrededor de 500 ha cada uno.

Al analizar la variación de suelo urbanizado para los años de estudio se observa el fuerte crecimiento que ha tenido Coronel (459 ha), equivalente al crecimiento de las dos comunas mayores: Concepción y Talcahuano. Destaca también el crecimiento relativo de la comuna de Chiguayante (18,3\%) mientras que el resto de las comunas presenta un crecimiento similar, entre un $11 \%$ y un $8 \%$.

Estos resultados muestran que el AMC posee una estructura "tradicional" con una gran mancha central y asentamientos que van reduciendo su tamaño hacia la periferia. Durante el periodo de estudio esta estructura tiende a ser modificada, apareciendo crecimientos importantes en sectores medios del área metropolitana.

Una vez que se ha obtenido el tamaño alcanzado por la ciudad para ambos periodos, un segundo indicador clave ha sido establecer la relación entre la superficie urbanizada y su población.

\section{Densidad urbana}

Un segundo indicador relevante es conocer el cambio de las densidades de población urbana. La densidad urbana pone en relación la población de un determinado territorio con la superficie urbanizada. 
Cuadro $\mathrm{N}^{\circ} 3$

Distribución y cambio de suelo urbanizado por comuna en el AMC, 1992-200

\begin{tabular}{|l|c|c|c|c|c|c|c|}
\hline \multicolumn{1}{|c|}{ Comuna } & $\begin{array}{c}\text { Superficie } \\
\text { urbanizada } \\
1992(\mathrm{ha})\end{array}$ & $\begin{array}{c}\text { Superficie } \\
\text { urbanizada } \\
\text { 2002 (ha) }\end{array}$ & $\begin{array}{c}\text { Variación } \\
1992- \\
2002(\mathrm{ha})\end{array}$ & $\begin{array}{c}\text { Variación } \\
\begin{array}{c}992-2002 \\
(\%)\end{array}\end{array}$ & $\begin{array}{c}\text { Superficie total } \\
\text { administrativa } \\
\text { comunal (ha) }\end{array}$ & $\begin{array}{c}\text { Urb./ } \\
\text { total } \\
1992(\%)\end{array}$ & $\begin{array}{c}\text { Urb./ } \\
\text { total } \\
2002(\%)\end{array}$ \\
\hline Concepción & 1.933 & 2.102 & 169 & 8,7 & 21.892 & 8,8 & 9,6 \\
Coronel & 1.110 & 1.569 & 459 & 41,4 & 27.806 & 4,0 & 5,6 \\
Chiguayante & 738 & 873 & 135 & 18,3 & 7.495 & 9,9 & 11,6 \\
Lota & 422 & 471 & 48 & 11,4 & 11.464 & 3,7 & 4,1 \\
Penco & 472 & 514 & 42 & 8,8 & 10.777 & 4,4 & 4,8 \\
San Pedro & 948 & 1.021 & 72 & 7,6 & 11.258 & 8,4 & 9,1 \\
Talcahuano & 2.832 & 3.141 & 308 & 10,9 & 14.578 & 19,4 & 21,5 \\
Tomé & 557 & 603 & 46 & 8,3 & 49.514 & 1,1 & 1,2 \\
Total & 9.013 & 10.293 & 1.279 & 14,2 & 154.782 & 5,8 & 6,6 \\
\hline
\end{tabular}

Fuente: Elaboración propia.

En el Cuadro $\mathrm{N}^{\circ} 4$ se muestra el cambio de la densidad de población urbana para los años de estudio, donde se observa que a nivel metropolitano esta ha disminuido levemente de 89 hab/ha a 85 hab/ha. Sin embargo, esta pérdida de densidad no es un proceso homogéneo en el territorio; la misma tabla señala la diferencia que existe entre comunas: mientras las del núcleo central pierden densidad (Concepción-Talcahuano) las Ilamadas "segunda corona" se densifican de forma importante (Chiguayante, Penco y San Pedro de la Paz) y, finalmente, las de la tercera corona pierden densidad (Coronel, Lota y Tomé).

Surgen así otras preguntas importantes ¿cuál es la causa del crecimiento urbano y la desdensificación a nivel metropolitano?, ¿qué tipo de ocupación es la que está determinando el consumo de suelo?, ¿ es un cambio en las tipologías de ocupación residencial o es debido al crecimiento de otros tipos de usos de suelo, como el industrial y comercial? Para responder a estas cuestiones se analizan a continuación los distintos tipos de ocupación de suelo según las categorías elaboradas.

\section{Tipologías de ocupación en el AMC}

A partir de la base de datos generada se elabora un mapa de tipologías de ocupación urbana para cada año de estudio (Figura $\mathrm{N}^{\circ}$ 5). La información obtenida se sintetiza en una tabla (Cuadro $N^{\circ} 5$ ) donde se muestra el total de superficie para cada tipología por año y la variación experimentada en el periodo analizado.

A nivel metropolitano se observa como tipología predominante la ocupación residencial, que para el año 1992 ocupa 7.089 ha, un $78,7 \%$ del total urbanizado y en el 2002 ocupa 7.868 ha, un $76,4 \%$ del total. Dentro del grupo de tipologías residenciales, la ocupación de alta densidad no muestra variación y mantiene las 228 ha, localizadas en la parte central de la comuna de Concepción. La ocupación de densidad media, junto con la discontinua de baja densidad, son las que poseen mayor superficie, representando un $66 \%$ del total urbanizado, y suman más de la mitad del crecimiento urbano total. 
Cuadro $\mathrm{N}^{\circ} 4$

Tabla de superficie urbana, población y densidad de población urbana para el AMC, 1992-2002

\begin{tabular}{|c|c|c|c|c|c|c|c|}
\hline \multirow[b]{2}{*}{ Comuna } & \multicolumn{3}{|c|}{1992} & \multicolumn{3}{|c|}{2002} & \multirow[b]{2}{*}{$\begin{array}{c}\text { Var. } \\
\text { densidad } \\
\text { 1992-2002 } \\
\text { (hab/ha) }\end{array}$} \\
\hline & $\begin{array}{c}\text { Superficie } \\
\text { urbana } \\
1992 \text { (ha) }\end{array}$ & $\begin{array}{c}\text { Población } \\
1992 \\
\text { (hab) }\end{array}$ & $\begin{array}{c}\text { Densidad } \\
1992 \\
\text { (hab/ha) }\end{array}$ & $\begin{array}{l}\text { Superficie } \\
\text { urbana } 2002 \\
\text { (ha) }\end{array}$ & $\begin{array}{l}\text { Población } \\
2002 \\
\text { (hab) }\end{array}$ & $\begin{array}{c}\text { Densidad } \\
2002 \\
\text { (hab/ha) }\end{array}$ & \\
\hline Concepción & 1.933 & 206.829 & 107 & 2.102 & 216.061 & 103 & -4 \\
\hline Coronel & 1.110 & 83.422 & 75 & 1.569 & 95.528 & 61 & -14 \\
\hline Chiguayante & 738 & 56.371 & 76 & 873 & 81.302 & 93 & 17 \\
\hline Lota & 422 & 50.256 & 119 & 471 & 49.089 & 104 & -15 \\
\hline Penco & 472 & 40.359 & 85 & 514 & 46.016 & 90 & 4 \\
\hline San Pedro & 948 & 67.817 & 71 & 1.021 & 80.447 & 79 & 7 \\
\hline Talcahuano & 2.832 & 248.532 & 88 & 3.141 & 250.348 & 80 & -8 \\
\hline Tomé & 557 & 49.269 & 88 & 603 & 52.440 & 87 & -1 \\
\hline Total & 9.013 & 802.855 & 89 & 10.293 & 871.231 & 85 & -4 \\
\hline
\end{tabular}

Fuente: Elaboración a partir de datos del INE y propios.

La tipología discontinua de bloques para el año 1992 ocupa un mínimo de superficie con 66 ha, pero su crecimiento es más del doble de su superficie, llegando a las 130 ha en el 2002. La ocupación residencial dispersa presenta en conjunto un receso importante del 2,3\%, localizado principalmente en la comuna de Chiguayante. Este receso se explica principalmente por la sustitución de viviendas irregulares (campamentos) por conjuntos de viviendas públicas, de construcciones adosadas y densidad de ocupación mediana.

La ocupación industrial en tanto representa el $15,2 \%$ y el $16,7 \%$ del total urbanizado en el $\mathrm{AMC}$, creciendo en 357 ha, siendo el segundo crecimiento de mayor superficie en el conjunto metropolitano, confirmando la importancia que posee para el sector la industria y sus actividades asociadas. El crecimiento comercial también presenta un desarrollo importante en el periodo creciendo un $71 \%$, localizado principalmente en áreas de nuevas centralidades.
Otro punto importante de analizar es la relación entre tipologías de ocupación y las densidades de población urbana para cada comuna. Como muestran los gráficos de la Figura $N^{\circ} 6$, existe una relación entre la variación de la densidad urbana y la variación de las tipologías de ocupación por comuna: aquellas comunas que muestran un receso importante en las tipologías discontinuas o de baja densidad de ocupación (Chiguayante) o bien en la ocupación industrial (San Pedro de la Paz) son las que presentan un aumento importante de densidad de población; aquellas que crecieron en suelo industrial y de baja densidad (Coronel, Talcahuano y Lota) presentan pérdida de densidad de población urbana. Una excepción podría ser Penco que pese a su crecimiento industrial y en baja densidad, tiene un leve aumento en densidad de población, probablemente debido a que la ocupación previa a 1992 era predominantemente de baja densidad. 
Figura $\mathrm{N}^{\circ} 5$

Mapa de tipologías de ocupación del AMC, 1992 y 2002

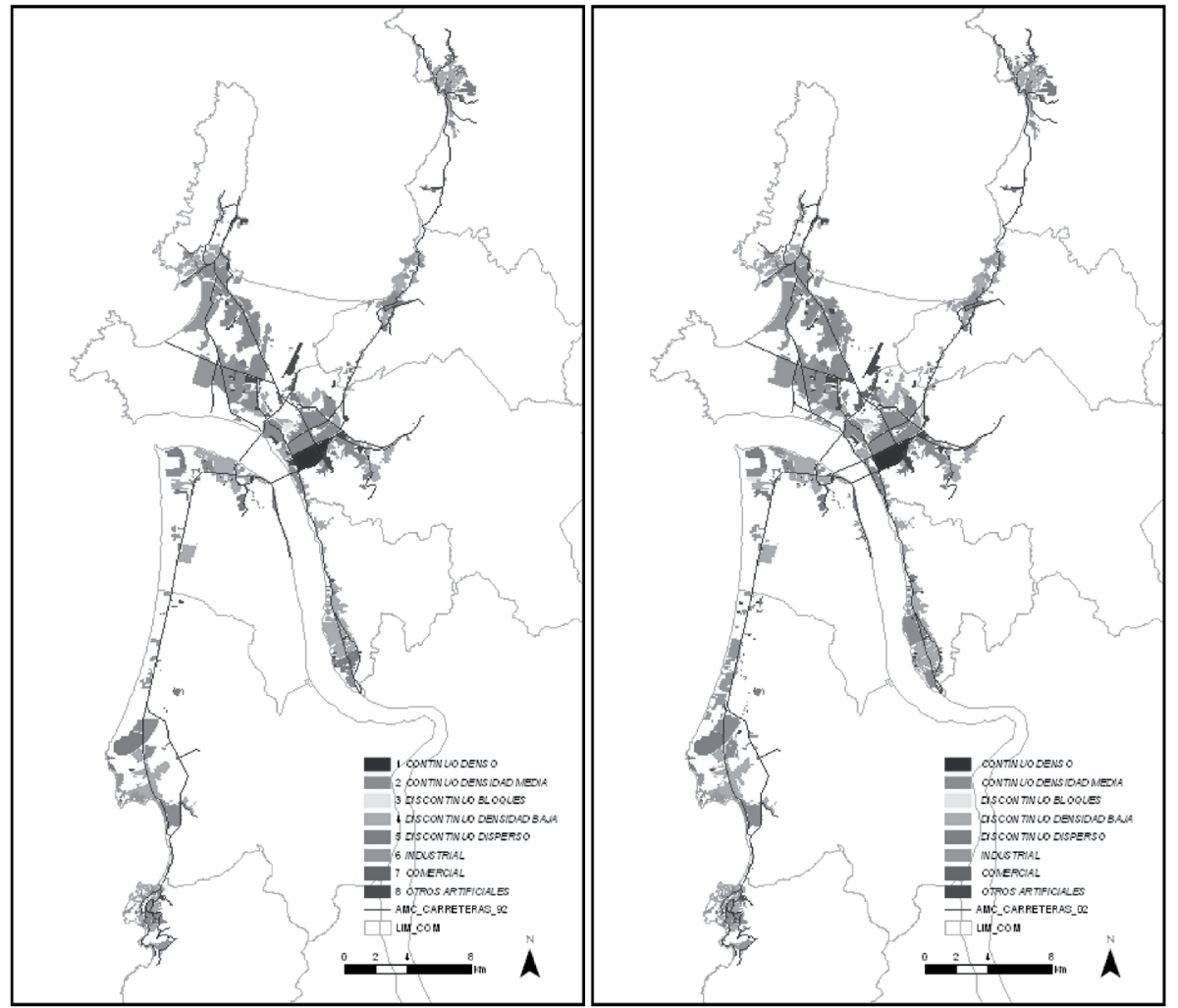

Fuente: Elaboración propia.

Cuadro $\mathrm{N}^{\circ} 5$

Distribución y cambio de suelo urbanizado por tipo de ocupación en el AMC, 1992-2002

\begin{tabular}{|l|r|r|r|r|}
\hline \multicolumn{1}{|c|}{ Tipo de ocupación } & 1992 (ha) & 2002 (ha) & Variación (ha) & Variación (\%) \\
\hline Residencial continuo denso & 228,4 & 228,4 & 0,0 & 0,0 \\
Residencial continuo medio & $2.961,0$ & $3.413,4$ & 452,4 & 15,3 \\
Residencial discontinuo bloques & 66,2 & 152,6 & 86,5 & 130,7 \\
Residencial discontinuo bajo & $2.819,0$ & $3.082,0$ & 263,0 & 9,3 \\
Residencial discontinuo disperso & $1.014,9$ & 991,7 & $-23,3$ & $-2,3$ \\
Industrial & $1.367,7$ & $1.724,9$ & 357,2 & 26,1 \\
Comercial & 88,3 & 159,8 & 71,5 & 80,9 \\
Otras áreas artificiales & 467,9 & 539,8 & 71,9 & 15,4 \\
Total áreas artificiales & 9013,4 & 10292,6 & 1279,2 & 14,2 \\
\hline
\end{tabular}

Fuente: Elaboración propia. 
Figura $\mathrm{N}^{\circ} 6$

Variación de densidad de población urbana por comuna (izquierda) y variación de la superficie de tipologías de ocupación en tres grandes grupos (derecha)
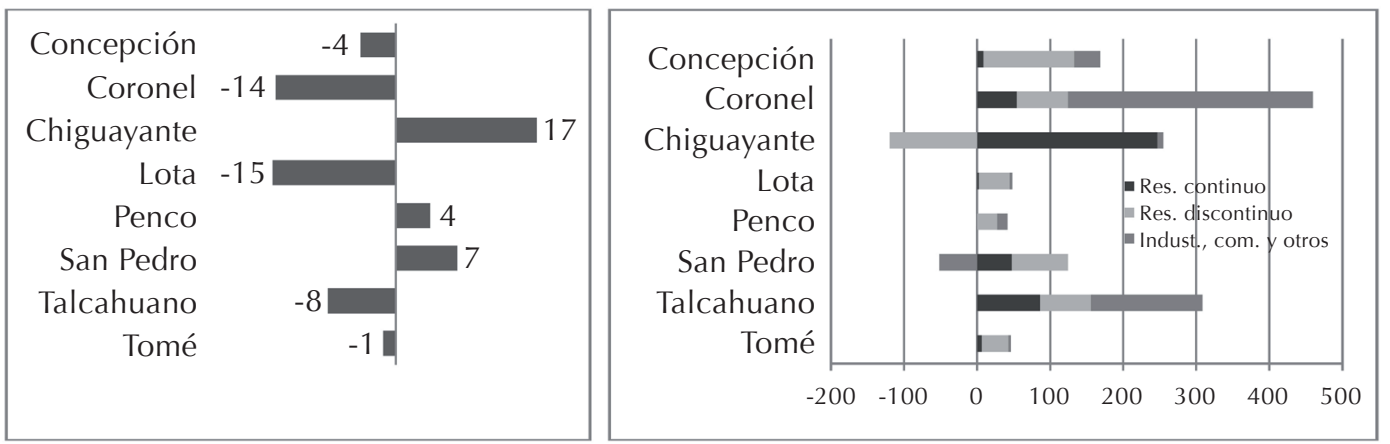

Fuente: Elaboración propia.

\section{Consideraciones finales}

Mediante la aplicación de una metodología basada en la fotointerpretación de imágenes aéreas e información censal se han podido conocer, desde una aproximación morfológica, los procesos recientes de ocupación urbana en una ciudad latinoamericana de tamaño medio, con mayor precisión científica. En su elaboración se ha desarrollado una metodología que permite a futuro comparar los datos obtenidos con la abundante información existente para ciudades europeas y norteamericanas. Se propone a su vez establecer protocolos similares en futuras investigaciones, que permitan el ensamblaje de los datos con otras investigaciones en ciudades chilenas y/o latinoamericanas.

De su aplicación en el AMC se obtuvo información relevante sobre el proceso de urbanización en diez años, tanto a nivel metropolitano como comunal, concluyendo sobre la configuración metropolitana, la distribución de sus tejidos y los procesos de ocupación recientes.

Durante el periodo estudiado, el AMC muestra un importante crecimiento en términos de superficie urbana. Comparado con lo ya urbanizado, esto equivale a crecer en diez años lo que ocupa una de sus comunas medianas o dos de sus comunas pequeñas; sin embargo, este crecimiento y la ocupación urbana total son aún una parte mínima del total de superficie disponible (no urbanizada) del territorio metropolitano, resultando ser significativamente menor al crecimiento urbano registrado para un periodo similar (19912000) en el AMS (Ducci, 2002).

Sin embargo, este crecimiento implica modificaciones cualitativas en la estructura y localización del suelo urbanizado: la ocupación urbana central predominante (Concepción-Talcahuano) se ha extendido cruzando la barrera hidrográfica del Biobío, sumando la zona con mayor concentración de suelo urbanizado de San Pedro de la Paz. El proceso más importante de localización de nuevo tejido es en la periferia de este núcleo, en un proceso de expansión y conurbación, intensificando la conexión con una segunda corona de municipios, Chiguayante y Penco, conexión que también va a esbozarse en los municipios alejados como Coronel, Lota y Tomé. El crecimiento de las comunas de la segunda corona apoya la tesis de una transición hacia una descentralización de los tejidos y funciones del sistema metropolitano; más que un modelo de crecimiento disperso como el descrito para las ciudades latinoamericanas por algunos autores (Rojas, 2009a; Janoschka, 2005), se observa una tendencia a conurbar los núcleos, ocupar intersticios y configurar una gran mancha metropolitana. 
Esta tendencia a colmatar los vacíos está presente en el Plan Regulador Metropolitano, en donde el suelo urbanizable es una gran mancha continua que cubre gran parte de la zona costera de la provincia, lo que agravará las externalidades negativas del proceso urbanizador en la calidad ambiental (Romero et al., 2009). Es importante señalar que la condición de desarrollo intermedio que actualmente tiene el modelo metropolitano es una condición propicia para orientar su desarrollo hacia un sistema urbano equilibrado, sustentado en la articulación de áreas naturales, de residencia y de producción.

Otro proceso relacionado con la sostenibilidad del AMC es la leve baja de densidad de población urbana a nivel metropolitano, que puede interpretarse como un proceso de ocupación del territorio menos eficiente, con un mayor consumo de suelo por habitante. Sin embargo, es necesario detenerse en otras características del proceso urbanizador. Primero, la desdensificación observada no es un proceso homogéneo en el territorio: mientras las comunas centrales y periféricas pierden densidad, las comunas de la zona media del área metropolitana presentan un alza importante. Segundo, estas variaciones de densidad urbana son resultado directo de la especialización de algunos tipos de ocupación; las comunas que más crecen en suelo industrial y residencial disperso o de baja densidad tienden a mostrar variaciones de densidad urbana muy por debajo del resto de las comunas.

El estudio de las tipologías de ocupación del AMC confirma que los principales factores de crecimiento urbano son el aumento de suelo industrial y residencial de densidad media-baja. En esto no hay sorpresa: el desarrollo metropolitano está íntimamente ligado a la producción industrial, a los puertos y a los recursos presentes en la región. Este desarrollo es similar al descrito para las ciudades latinoamericanas que han seguido en su proceso de crecimiento una tendencia más bien horizontal, donde ha predominado la informalidad, los barrios cerrados y los parques industriales (Borja, 2001). No obstante, el AMC muestra una diferencia importante a los casos de estudio presentados, en cuanto a las áreas residenciales en la década estudiada: el aumento de tipologías residenciales compactas de densidad media, la tipología de bloques y el receso de la tipología dispersa, revelan una leve tendencia metropolitana a una ocupación más densa o, a lo menos, de mediana densidad. Estos cambios pueden atribuirse a factores relacionados con la empresa inmobiliaria: la búsqueda de rentabilidad en la urbanización (minimización de costes de urbanización) y una estrategia de mercado progresiva (una oferta desarrollada por etapas, que ofrece primero productos exclusivos y de baja densidad para luego ofrecer densidades más compactas hasta llegar a edificios de departamentos); pero también se relacionan con políticas estatales, como la sustitución de asentamientos informales por vivienda social (de una ocupación dispersa y sin urbanización a una ocupación medianamente densa y con equipamientos básicos).

A modo de síntesis se puede concluir que las transformaciones estudiadas son de características distintas al modelo de expansión y fragmentación urbana, citado frecuentemente para las ciudades latinoamericanas en este periodo, mostrando variaciones hacia una fase que se podría denominar como modelo intermedio: un crecimiento moderado del suelo urbano, con tendencia a localizar nuevos tejidos en el área media metropolitana y conformar una continuidad de la mancha urbana, principalmente a través de ocupación industrial y tipologías residenciales de mediana densidad y un receso de la ocupación dispersa hacia ocupaciones residenciales más compactas y densas.

\section{Agradecimientos}

Los autores agradecen la valiosa colaboración de las siguientes instituciones: Comisión Nacional de Investigación Científica y Tecnológica (CONICYT); Instituto Nacional de Estadísticas de Chile (INE); Ministerio de Vivienda y Urbanismo de Chile (MINVU); Departamento de Geografía de la Universidad de Concepción; y Centro de Política del Suelo y Valoraciones de la Universidad Politécnica de Cataluña.

\section{Referencias bibliográficas}

AGUAYO, M.; WIEGAND, T.; AZÓCAR, G.; WIEGAND, K. \& VEGA, C. Revealing driving forces of mid-cities urban growth patterns 
using spatial modeling: a case study of Los Angeles (Chile). Ecology and Society, 2007, vol. 12, No 1. Disponible en Internet: http:// www.ecologyandsociety.org/vol12/iss1/art13/

AZÓCAR, G. y SANHUEZA, R. Evolución del uso del suelo en las cuencas hidrográficas de las lagunas de la comuna de San Pedro de la Paz, Región del Biobío: análisis histórico y tendencias. Revista Geográfica de Chile. Terra Australis, 1999, № 44, p. 63-78.

AZÓCAR, G.; AGUAYO, M.; HENRÍQUEZ, C.; VEGA, C. y SANHUEZA, R. Patrones de crecimiento urbano en la Patagonia chilena: el caso de la ciudad de Coyhaique. Revista de Geografía Norte Grande, 2010, No 46 , p. 85-104.

AZÓCAR, G.; HENRÍQUEZ, C. y SANHUEZA, R. Cambio en los patrones de crecimiento en una ciudad intermedia: el caso de Chillán en Chile Central. EURE, 2003, vol. XXIX, No 87, p. 79-92.

AZÓCAR, G.; HENRÍQUEZ, C.; VALENZUELA, C. y ROMERO, H. Tendencias sociodemográficas y segregación socioespacial en Los Ángeles, Chile. Revista de Geografía Norte Grande, 2008, № 41, p. 103-128.

AZÓCAR, G.; ROMERO, H.; SANHUEZA, R.; VEGA, C.; AGUAYO, M. \& MUÑOZ, M. Urbanization patterns in chilean mid-sized cities and their impacts on the social restructuring of urban space: a case study in Santa Maria de Los Angeles, Central Chile. Land Use Policy, 2007, vol. 24, № 1, p. 199-211.

BAERISWYL, S. Patrones de ocupación del Gran Concepción, A través del modelo de consumo de suelo. En: Santiago, Coloquio del País Urbano al País Metropolitano, 2007.

BORJA, J. El gobierno del territorio de las ciudades latinoamericanas. Revista Instituciones y Desarrollo, 2001, № 8 y 9, p. 83-142.

BORSDORF, A. El desarrollo urbano de Valdivia. Estudio de caso de una ciudad mediana. Espacio y Desarrollo, 2000, № 12, p. 45-82.

BORSDORF, A. Hacia la ciudad fragmentada. Tempranas estructuras segregadas en la ciudad latinoamericana. Scripta Nova. Revista electrónica de geografía y ciencias sociales, 2003, vol. VII, No 146(122). Disponible em Internet: http://www.ub.es/geocrit/ sn/sn-146(122).htm

BORSDORF, A. e HIDALGO, R. Los Mega-diseños residenciales vallados en las periferias de las metrópolis latinoamericanas y el advenimiento de un nuevo concepto de ciudad. Alcances en base al caso de Santiago de Chile. Scripta Nova. Revista electrónica de geografía y ciencias sociales, 2005, vol. IX, No 194 (03). Disponible en Internet: http://www. ub.es/geocrit/sn/sn-194-03.htm

CARIOLA, C. y LACABANA, M. Globalización y desigualdades socio-territoriales: la expansión de la periferia metropolitana de Caracas. EURE, 2003, vol. XXIX, № 87 p. 5-21.

CHUVIECO, E. Aportaciones de la Teledetección espacial a la cartografía de ocupación del suelo. Anales de Geografía de la Universidad Complutense, 1985, No 5, p. 29-48. Disponible en Internet: http://revistas.ucm.es/ ghi/02119803/articulos/AGUC8585110029A. PDF

COMISIÓN EUROPEA. Estrategia territorial europea. Hacia un desarrollo equilibrado y sostenible del territorio de la Unión Europea. Bruselas: Comisión Europea, 1999. Disponible en Internet: http://ec.europa.eu/ regional_policy/sources/docoffic/official/reports/pdf/sum_es.pdf

DUCCI, M. E. Área urbana de Santiago 1991-2000: expansión de la industria y la vivienda. EURE, 2002, vol. XXVIII, No 85 , p.187-207.

EUROPEAN ENVIRONMENT AGENCY (EEA). Land accounts for Europe 1990-2000. Towards integrated land and ecosystem accounting. Copenhagen: EEA, Report No 11, 2006.

HENRÍQUEZ, C.; AZÓCAR, G. \& ROME$\mathrm{RO}, \mathrm{H}$. Monitoring and modeling the urban growth of two mid-sized Chilean cities. Habitat International, 2006, vol. 4, No 30, p. 945-964. 
HIDALGO, R. De los pequeños condominios a la ciudad vallada: las urbanizaciones cerradas y la nueva geografía social en Santiago de Chile (1990-2000). EURE, 2004, vol. $X X X, N^{\circ} 91$, p. 29-52.

HIDALGO, R. ¿Se acabó el suelo en la gran ciudad?: Las nuevas periferias metropolitanas de la vivienda social en Santiago de Chile. EURE, 2007, vol. XXXIII, No 98, p. 57-75.

INSTITUTO NACIONAL DE ESTADÍSTICAS (INE). Chile: División Político-Administrativa y Censal 2001. Santiago: INE, 2001. Disponible en Internet: http://www.ine.cl/canales/chile_estadistico/territorio/ division_politico_administrativa/pdf/dpa2001.pdf

INSTITUTO NACIONAL DE ESTADÍSTICAS (INE). Censo Nacional de población y vivienda. Santiago: INE, 2002.

JANOSCHKA, M. El nuevo modelo de la ciudad latinoamericana: fragmentación y privatización. EURE, 2002, vol. XXVIII, № 85, p. 11-29.

JANOSCHKA, M. De ciudades dispersas a ciudades perforadas. Una nueva fase de transición demográfica y sus consecuencias morfológicas. En: DE MATTOS, C.; FIGUEROA, Ó.; GlMÉNEZ, R.; ORELLANA, A. y YÁÑEZ, G. (eds.). Gobernanza, competitividad y rede. Santiago: Instituto de Estudios Urbanos y Territoriales, Pontificia Universidad Católica de Chile, Colección EURE-Libros, 2005, p. 151-172.

JANOSCHKA, M. El modelo de ciudad latinoamericana. Privatización y fragmentación del espacio urbano de Bueno Aires: el caso del Nordelta. En: PONCE HERRERO, G. (ed.). La ciudad fragmentada: nuevas formas de hábitat. Alicante: Universidad de Alicante, 2006, p. 259-263.

LÓPEZ, M. Expansión de las ciudades. EURE, 1981, vol. VIII, No 22, p. 31-42.

MINISTERIO DE MEDIO AMBIENTE (MMA). Estrategias de medio ambiente urbano. Madrid: Centro de Publicaciones Secretaría General Técnica, Ministerio de Medio Ambiente, 2006. Disponible en Internet: http://www. bcnecologia.net/documentos/estrategia.pdf
OBSERVATORIO DE LA SOSTENIBILIDAD EN ESPAÑA (OSE). Cambios de ocupación del suelo en España, implicaciones para la sostenibilidad. Madrid: Editorial OSE, 2006.

OBSERVATORIO URBANO (OU). Medición de la superficie ocupada por las ciudades de Chile de más de 15.000 habitantes: 1993-2003. Santiago: Ministerio de Vivienda y Urbanismo, 2007. Disponible en Internet: http://www.observatoriourbano. cl/docs/pdf/Medici\%C3\%B3n\%20de\%20 la $\% 20$ superficie $\% 20$ ocupada $\% 20$ por $\% 20$ las $\% 20$ ciudades $\% 20 \mathrm{de} \% 20$ Chile $\% 20 \mathrm{de} \% 20$ m\%C3\%A1s\%20de\%2015.000\%20habitantes\%201993\%20-\%202003\%20Noviembre\%202003\%20vers\%202.pdf

PAUChARD, A.; AGUAYO, M.; PEÑA, E. \& URRUTIA, R. Multiple effects of urbanization on the biodiversity of developing countries: the case of a fast-growing metropolitan area (Concepción, Chile). Biological Conservation, 2006, N 127, p. 272-281.

PÉREZ, L. y SALINAS, E. Crecimiento urbano y globalización: transformaciones del Área Metropolitana de Concepción, Chile, 1992-2002. Scripta Nova. Revista Electrónica de Geografía y Ciencias sociales, 2007, vol. $\mathrm{XI}, \mathrm{N}^{\circ}$ 251. Disponible en Internet: http:// www.ub.es/geocrit/sn/sn-251.htm

PLATA, W.; GÓMEZ, M. y BOSQUE, J. Cambio de usos de suelo y expansión urbana en la comunidad de Madrid (1990-2000). Scripta Nova. Revista Electrónica de Geografía y Ciencias Sociales, 2009, vol. XIII, $\mathrm{N}^{\circ}$ 293. Disponible en Internet: http://www. ub.es/geocrit/sn/sn-293.htm

PORTAS, N. De una ciudad a otra: perspectivas periféricas. En: MARTíN, A. Lo urbano en 20 autores contemporáneos. Barcelona: Ediciones UPC, 2004, p. 221-229.

ROJAS, C.; MUÑIZ, I. y GARCÍA-LÓPEZ, M. Estructura urbana y policentrismo en el Área Metropolitana de Concepción. EURE, 2009a, vol. 35, No 105, p. 47-70.

ROJAS; C.; OPAZO, S. y JAQUE, E. Dinámica y patrones de crecimiento urbano del Área Metropolitana de Concepción. Tenden- 
cias de las últimas décadas. En: HIDALGO, R.; DE MATTOS, C. y ARENAS, F. (eds.). Chile: del país urbano al país metropolitano. Santiago: Instituto de Geografía, Instituto de Estudios Urbanos y Territoriales, Pontificia Universidad Católica de Chile, Serie GEOlibros 12, Colección EURE-libros, 2009b, p. 257-268.

ROMERO, H.; MOSCOSO, C. y SMITH, P. Lecciones y conclusiones sobre la falta de sustentabilidad ambiental del crecimiento espacial de las ciudades chilenas. En: HIDALGO, R.; DE MATTOS, C. y ARENAS, F. (eds.). Chile: Del país urbano al país metropolitano.
Santiago: Instituto de Geografía, Instituto de Estudios Urbanos y Territoriales, Pontificia Universidad Católica de Chile, Serie GEOlibros y EURE-libros, 2009, p. 89-108.

ROVIRA, A. Puerto Montt: el paso de una ciudad menor a centro de desarrollo interregional en una ciudad del sur de Chile. Espacio y Desarrollo, 2000, No 12, p. 83-102.

TASCHNER, S. \& BÓGUS, L. São Paulo, uma metrópole desigual. EURE, 2001, vol. XXVII, No 80, p. 87-120. Disponible en Internet: http://www.eure.cl//articulos/417/saopaulo-uma-metropole-desigual/0022 